Buana Sains Vol 17 No 2: 115 - 124, 2017

\title{
PEMELIHARAAN HAZARD DI PADANG GOLF MATOA NASIONAL, JAKARTA SELATAN
}

\author{
Samsud Dlukha, Sitti Wardiningsih, Yusi Febriani, Ray March Syahadat, \\ Priambudi Trie Putra \\ Program Studi Arsitektur Lanskap, Fakultas Teknik Sipil dan Perencanaan, \\ Institut Sains dan Teknologi Nasional
}

\begin{abstract}
Padang Golf Matoa Nasional is a 18 hole golf course that located in South Jakarta and designed with international standards. A game area of golf courses consist of several zones. The zones need to be maintained by form of ideal and maintenance activities. This study focuses on the maintenance of hazard zones (bunkers, water hazards, and rough) as important part of the golf game area. The purpose of this article provides recommendations on system maintenance hazard in Padang Golf Matoa Nasional so that the quality of the landscape and the game remains optimal. The results obtained in general maintenance hazard zone has been good. To realize optimal results, it is required labor ratios ranging from 1:0,1 to 1:0,3. Furthermore, it is needed to increase the number and renewing putty knife and hoe for effective use of maintenance process.
\end{abstract}

Keywords: Bunker, game area, golf course, rough, water hazard

\section{Pendahuluan}

Padang Golf Matoa Nasional merupakan salah satu lapangan golf yang berada di kawasan Jakarta Selatan. Padang Golf Matoa Nasional merupakan padang golf dengan konsep arboretum dan sebagai area pelestarian pohon langka sehingga banyak pohon buah asli Indonesia yang ditanam di kawasan tersebut. Padang Golf Matoa Nasional memiliki 18 bole dan dirancang dengan standar internasional dengan luas \pm 60 ha terdiri dengan pohon dan tanaman eksotis. Luas area permainan $\pm 49,4$ ha.

Lanskap lapangan golf adalah lingkungan di sekitar lapangan golf yang berupa tanaman nonrumput dan area permainan yang berupa rumput. Lapangan golf tanpa adanya pohon akan terlihat gundul dan pemain akan merasakan pentingnya pohon dan tanaman ornamental. Aspek estetis adalah hal yang utama dalam permainan golf.).

Lily (1999) mendefinisikan bahwa lapangan golf sebagai salah satu bentuk ruang terbuka hijau, dibuat sebagai sarana olahraga yang rekreatif, dengan tanaman rumput yang mendominasinya. Selain rumput, terdapat jenis tanaman lain, yaitu pohon yang tidak hanya bermanfaat memperbaiki iklim mikro, tetapi juga berfungsi sebagai rintangan alami dalam permainan golf. Menurut Emmons (2000), area permainan suatu lapangan golf terdiri dari beberapa zona antara lain tee box, fairway, green, rough, serta hazard. 
Hazard merupakan suatu komponen penting dalam lapangan golf yang merupakan rintangan di lapangan. Rintangan-rintangan tersebut diletakkan di fairway, rough, dan sekitar green. Selain berfungsi sebagai rintangan, daerah ini juga berfungsi sebagai tempat akhir pembuangan air drainase dan bermanfaat sebagai air irigasi. Mengingat pentingnya bazard maka perlu dilakukan pemeliharaan yang intensif.

Pemeliharaan dilakukan dengan tujuan menjaga dan merawat areal dengan segala fasilitas yang ada di dalamnya agar kondisinya tetap baik atau sedapat mungkin mempertahankannya pada keadaan yang sesuai dengan tujuan rancangan dan desain awal. Pemeliharaan dikenal dengan pemeliharaan ideal dan pemeliharaan fisik. Pemeliharaan ideal adalah pemeliharaan yang mempertahankan tujuan, fungsi, dan desain semula. Pemeliharaan fisik meliputi pekerjaan untuk tetap menjaga keindahan, keasrian, kenyamanan, dan keamanan (Arifin dan Arifin 2005).

Menurut Arifin dan Arifin (2005), pemeliharaan ideal akan berjalan dengan baik apabila didukung oleh upaya-upaya berikut ini:

1. perencanaan dan perancangan taman yang didesain sederhana;

2. penggunaan elemen taman yang mudah ditemukan;

3. pemilihan sistem struktur yang kuat dan awet serta pemilihan bahan-bahan perkerasan yang sesuai;

4. pembuatan pola sirkulasi yang rasional dan jelas; dan

5. perlengkapan taman yang memadai, penerangan lampu pada malam hari, dan jaringan utilitas yang ada di bawah tanah harus direncanakan dengan baik sehingga tidak terjadi bongkar pasang pada taman dalam hal ini permukaannya.
Sternloff dan Warren (1984) menyatakan bahwa pemeliharaan fisik memiliki dua sistem pemeliharaan, yaitu pemeliharaan korektif dan preventif. Pemeliharaan korektif menitikberatkan pada penanganan masalah yang terjadi. Pemeliharaan preventif menekankan pada identifikasi dan penyelesaian masalah yang mungkin terjadi sehingga sering dikatakan sebagai kunci sukses dalam meminimalisasi perawatan kerusakan pada lanskap.

Petrick et al. (1999), menyatakan bahwa kualitas servis serta kondisi lapangan berhubungan kepada kepuasan pemain. Selanjutnya Shmanske (1999), juga menyatakan bahwa kualitas lapangan golf dapat dinilai dari keindahan serta kelayakan lapangan golf untuk dimainkan. Untuk itu hazard yang terdiri atas bunker, water hazard, dan rough sebagai salah satu komponen utama dalam lapangan golf perlu mendapatkan perhatian khusus terutama dalam hal pemeliharaannya. Tujuan dari artikel ini yaitu memberikan rekomendasi sistem pemeliharaan hazard di Padang Golf Matoa Nasional yang dirasa masih kurang dalam mencapai keberlanjutan. Adapun kerangka pikir dari artikel ini dapat dilihat pada Gambar 1.

\section{Metode Penelitian}

Studi dilaksanakan selama tiga bulan, mulai dari Maret 2016 sampai Juni 2016. Lokasi studi dilaksanakan di Padang Golf Matoa Nasional terletak di Jl. Moh Kahfi I Km. 7, Ciganjur, Jakarta Selatan (Gambar 2). Metode yang digunakan analisis kualitatif dan kuantitatif. Data diperoleh dari data primer yang didapat dari pengamatan secara langsung di lapangan dan dengan melakukan diskusi dengan tenaga kerja yang bekerja pada tempat tersebut dan pihak-pihak terkait. Selain itu dilakukan juga wawancara 
dengan tenaga kerja dan pihak-pihak terkait dalam kegiatan pengelolaan lanskap, sedangkan data sekunder diperoleh dari studi literatur. Pengumpulan data dilakukan dengan mengumpulan data primer dan sekunder. Data primer diperoleh dari hasil pengamatan secara langsung di lapangan dan wawancara dengan tenaga kerja dan pihak-pihak terkait. Data sekunder diperoleh dari studi literatur yang berasal dari buku-buku, jurnal, dan sumber pustaka lainnya. Untuk mengetahui kapasitas kerja dilakukan pada pekerja pemeliharaan yang bekerja secara efektif digunakan rumus sebagai berikut:

Volume pekerjaan $\left(\mathrm{m}^{2}\right) \mathrm{X}$ pekerjaan/bulan Kapasitas Kerja/Jam

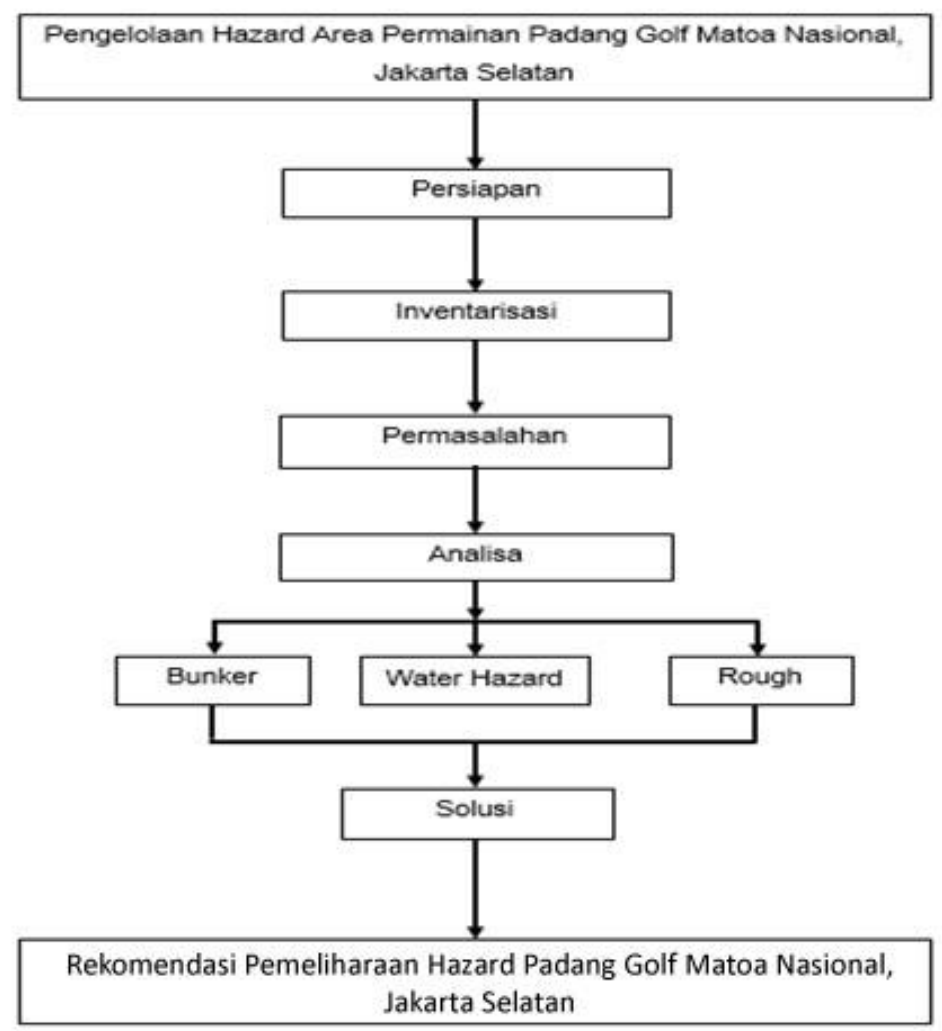

Gambar 1. Kerangka Berpikir

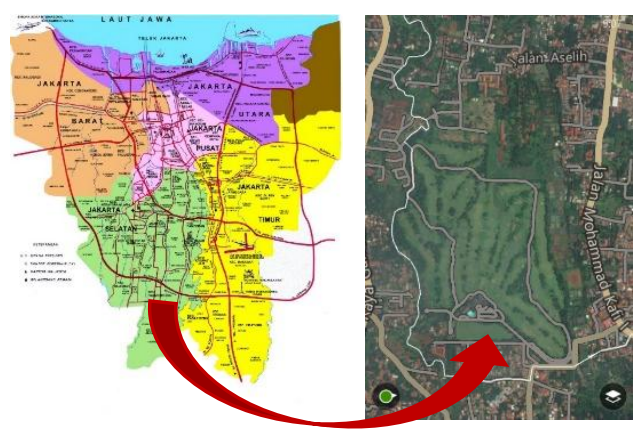

Gambar 2. Peta Lokasi Padang Golf Matoa Nasional (PGMN) 


\section{Hasil dan Pembahasan}

Lokasi Padang Golf Matoa Nasional berada di Ciganjur, Jakarta Selatan. Padang dengan konsep arboretum ini menawarkan udara segar dan alami tanpa harus pergi jauh keluar kota. Fasilitas Padang Golf Matoa Nasional dilengkapi dengan driving range, restoran, kolam renang, conference room, serta locker room dengan sauna. Konsep golf yang terletak selaras dengan lingkungan alam telah dikembangkan dan disempurnakan selama bertahun-tahun oleh tim penggemar golf, naturalis, dan ahli desain. Padang Golf Matoa Nasional ini memiliki 18 bole dan ini dirancang dengan standar internasional. Pada sebagian besar padang golf 18 lubang, total pukulan adalah 72 kali yang terdiri dari 4 lubang ber-par 3, 10 lubang ber-par 4, dan 4 lubang ber-par 5. Padang Golf Matoa Nasional dengan luas \pm 60 hektar terdiri dengan pohon dan tanaman eksotis. Luas area permainan \pm 49,4 ha. Untuk membantu kelancaran kegiatan pemeliharaan, pihak pengelola Padang Golf Matoa Nasional telah merancang struktur organisasi divisi course maintenance yang terdiri atas beberapa bagian. Untuk penanganan hazard dilakukan oleh bagian landscape dan turfgrass (Gambar 3).

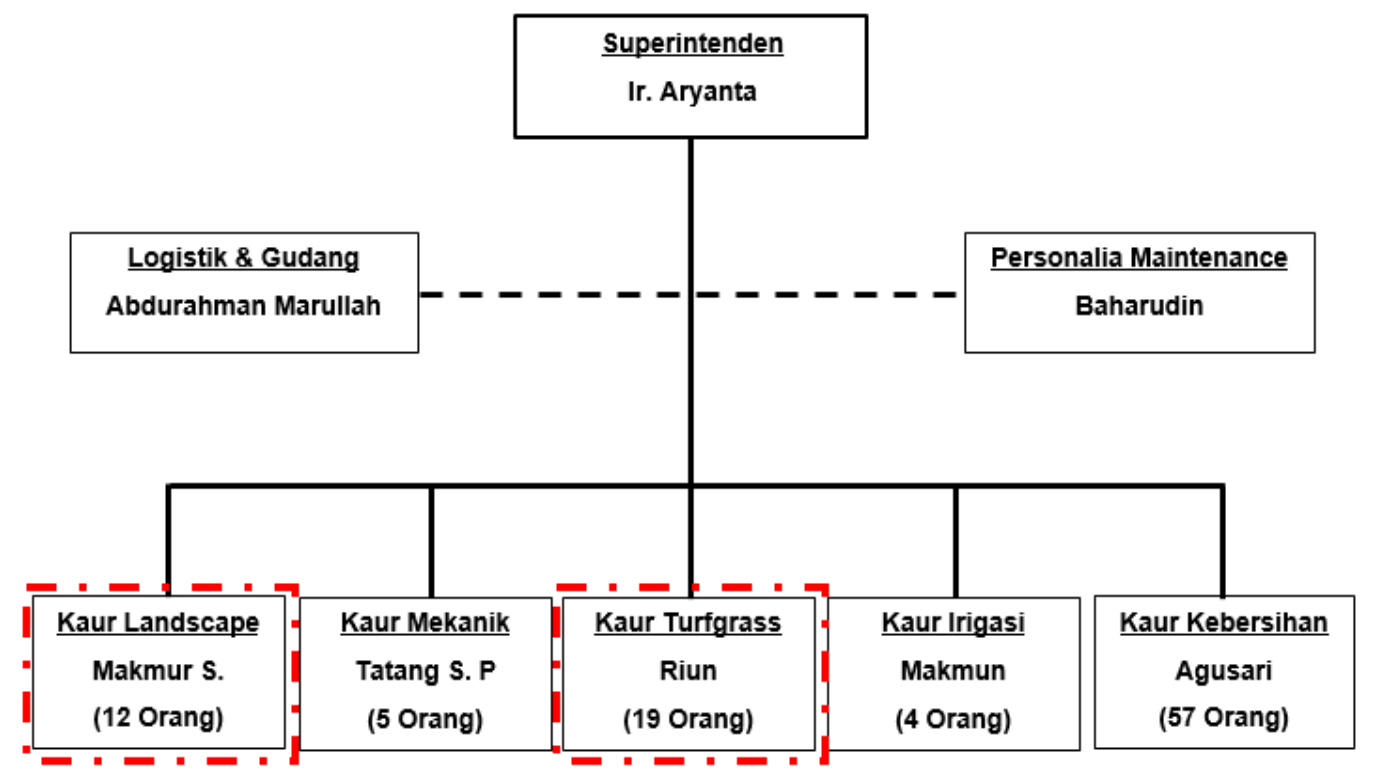

Gambar 3. Struktur Organisasi Divisi Course Maintenance

Hazard merupakan suatu rintangan di lapangan, biasanya berupa bak pasir (bunker), water hazard, dan pepohonan di sepanjang daerah rough (Setyaningsih, 1999). Hazard juga dapat menambah nilai keunikan pada lapangan golf (Merinda, 2002). Bunker merupakan salah satu hazard yang berupa area cekungan kosong yang biasanya ditutupi dengan pasir (Beard, 1982) (Gambar 4). Pembuatan bunker tidak memiliki batas ketentuan ukuran dan bentuk. Tujuan utama pembuatan bunker adalah untuk mempersulit pemain yang salah dalam melakukan pukulan. Pembuatan bunker tidak memiliki batas ketentuan ukuran dan bentuk. Pasir untuk bunker biasanya menggunakan jenis pasir yang berwarna cerah seperti putih, coklat, atau abu-abu. Menurut Beard (1982), kedalaman bunker paling sedikit mencapai 4 inchi $(10 \mathrm{~cm})$ untuk bagian dasar dan sekitar 2 inchi (5 $\mathrm{cm}$ ) untuk bagian permukaan. 


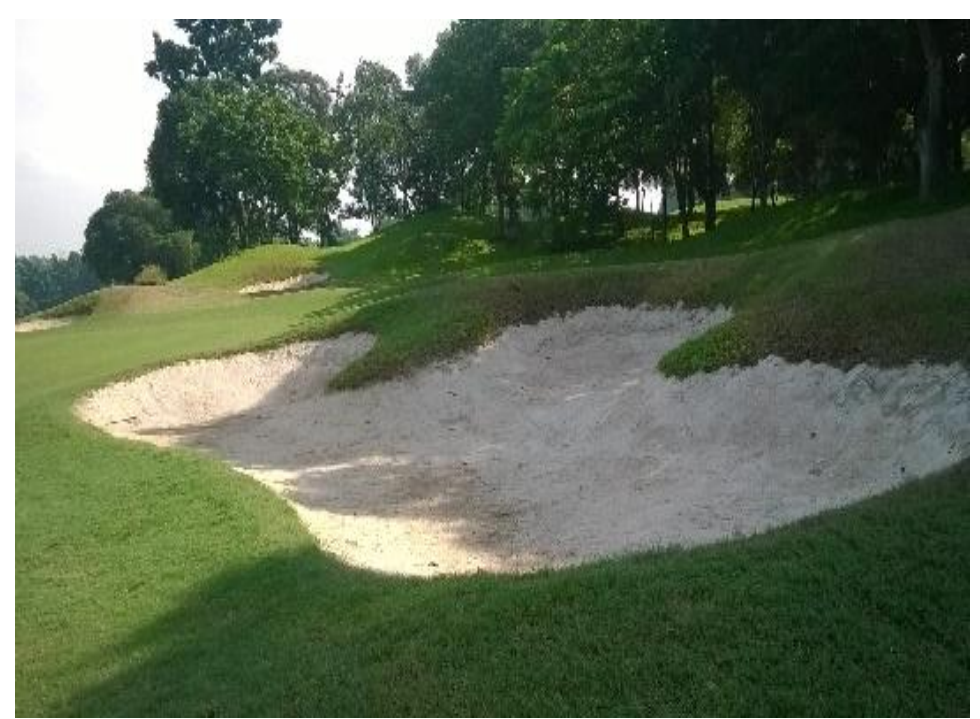

Gambar 4. Bunker di Padang Golf Matoa Nasional

Padang Golf Matoa Nasional memiliki 79 bunker yang tersebar pada 18 bole, dengan total luas per bole sebesar $1283 \mathrm{~m}^{2}$. Pemeliharaan bunker dilakukan oleh pihak divisi turfgrass. Pelaksanaan kegiatan pemeliharaan bunker meliputi raking dan edging. Kegiatan penggemburan (raking) di Padang Golf Matoa Nasional sudah cukup baik. Alat yang digunakan untuk kegiatan raking yaitu garpu tanah. Raking dilakukan setiap hari pada pagi hari sebelum pemain datang dan pekerja melakukan kegiatan pemeliharaan lainnya. Tujuan dilakukan raking adalah untuk menggemburkan tanah agar bola yang jatuh pada bunker tidah memantul. Kendala yang dialami dalam kegiatan edging adalah kurangnya tenaga kerja sehingga terdapat beberapa bunker yang pasirnya mengeras.

Edging dilakukan setiap seminggu sekali atau jika rumput telah melewati batas antara rumput dengan pasir. Alat yang digunakan adalah kape atau dengan menggunakan alat pembatas edging bunker yaitu trimmer. Kendala dalam pelaksanaan edging yaitu kurangnya tenaga kerja dan alat yang digunakan kurang memadai baik jumlah maupun kondisi alat sehingga pengerjaan edging kurang efektif.
Water hazard merupakan salah satu bentuk hazard berupa danau/kolam buatan yang ada di area fairway atau rough (Gambar 5). Fungsi water hazard adalah untuk mempersulit pemain karena pemain akan terkena penalti apabila bola yang dipukul masuk ke dalam danau/kolam buatan. Jumlah water hazard di Padang Golf Matoa Nasional berjumlah 4, masing-masing berada di bole 2, bole 12, bole 16, dan bole 17 .

Pemeliharaan water hazard dibawahi oleh divisi lanskap. Kegiatan penambahan air dilakukan setiap hari dan pembersihan dikerjakan seminggu sekali. Kegiatan pemeliharaan lainnya adalah memangkas rumput di tepian danau/kolam buatan (edging). Alat yang digunakan adalah cangkul, golok, dan mesin pemotong rumput. Kegiatan pemeliharaan water hazard dikerjakan oleh 2 atau 3 orang pekerja untuk membersihkan sampah-sampah plastik dan membersihkan rumput yang tumbuh di dalam kolam buatan tersebut. Kegiatan pemeliharaan water hazard ini sudah cukup baik. Rough merupakan area rumput yang menjadi batas terluar suatu area permainan golf dengan lingkungan sekitar atau area permainan lainnya. Pada 
daerah ini dibangun service road dan ditanami pepohonan yang berfungsi sebagai border. Rough berfungsi untuk melindungi daerah-daerah yang mungkin dapat membahayakan pemain yang salah dalam melakukan pukulan (Setyaningsih,
1999). Pemilihan jenis tanaman yang tepat dan penempatan yang baik pada lanskap lapangan golf memiliki empat fungsi utama yang saling berhubungan, yaitu fungsi secara arsitektural, teknik, estetika, dan juga ekonomi (Beard, 1982).

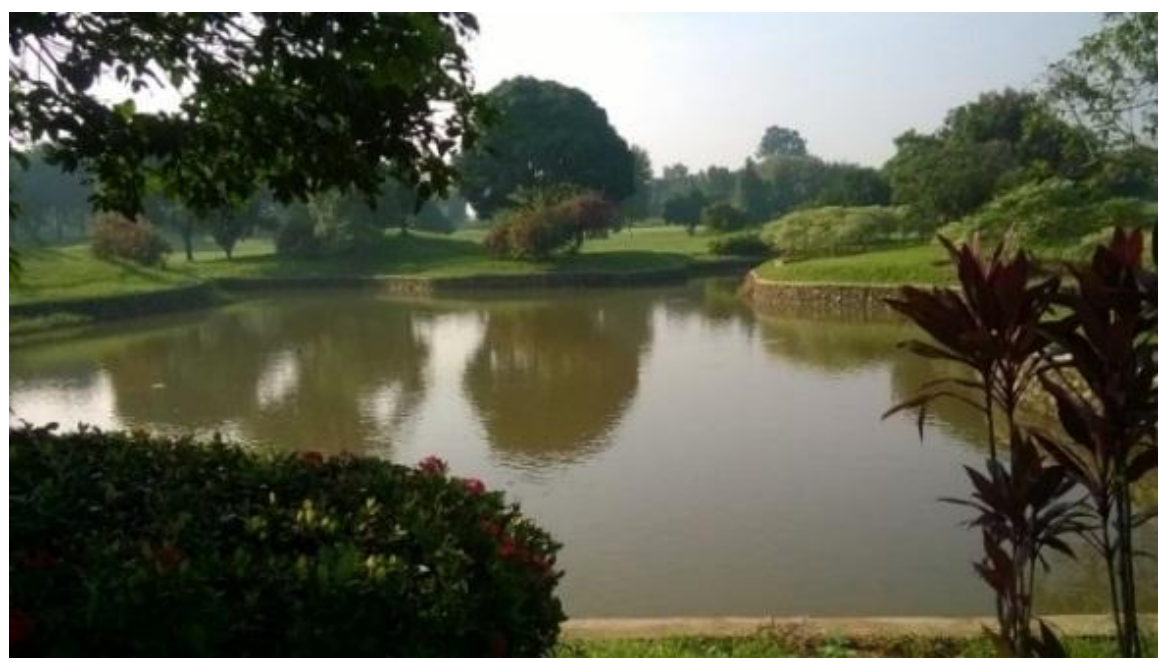

Gambar 5. Water Hazard (Danau/Kolam Buatan)

Fungsi pohon secara arsitektural antara lain sebagai rintangan alami bagi pemain golf untuk penempatan bola di permainan golf, alat penentu jarak yang alami, dan referensi point saat bola mendarat pada garis area permainan. Selanjutnya, pohon juga berfungsi sebagai kontrol dalam penempatan bola agar tidak keluar area permainan dan menciptakan target utama, yaitu daerah green, serta melindungi pemain golf dari sinar matahari yang menyilaukan. Pohon juga bermanfaat sebagai tempat istirahat dan mencegah bola hilang saat keluar area permainan.

Fungsi pohon secara teknik yaitu sebagai pengontrol aliran udara (sirkulasi) dan pengubah lingkungan, contohnya sebagai pemecah arah angin. Pohon juga berfungsi sebagai alat konservasi seperti pengontrol erosi dan preservasi habitat satwa. Selanjutnya secara teknik, pohon juga berfungsi untuk pengamanan dari pukulan yang tidak terarah bagi pemain golf dan properti lainnya, serta membatasi dari sesuatu yang mengganggu serta pemberi rasa nyaman bagi pemain golf.

Secara estetika pohon juga memiliki beberapa fungsi. Pohon memiliki fungsi sebagai pemecah kemonotonan di sepanjang daerah permainan dan penghubung dari bentukan-bentukan yang ada di lapangan golf. Pohon juga dapat memberi kesan tertentu seperti menghasilkan kontras, variasi, focal point, dan pemberi tekanan (emphasis) terhadap suatu titik yang menjadi pusat perhatian.

Jumlah rough di Padang Golf Matoa Nasional adalah 18 rough dan didominasi oleh pohon-pohon buah asli Indonesia seperti pohon matoa (Pometia pinnata), pohon mangga (Mangifera indica), pohon rambutan (Nephelium lappaceum), pohon mahoni (Swietenia mahogani), dan pohon belimbing (Averrboa bilimbi) yang berjumlah sebanyak 2885 pohon. 
Pemeliharaan rough dilakukan oleh pihak divisi lanskap. Pelaksanaan kegiatan pemeliharaan rough meliputi pembersihan dan pemangkasan. Kegiatan pembersihan merupakan kegiatan penyapuan di area permainan. Kegiatan penyapuan dilakukan oleh tenaga kerja perempuan dengan frekuensi pelaksanaan pembersihan dilakukan setiap hari, pada pagi dan siang hari. Jumlah tenaga kerja untuk kegiatan pembersihan seluruh area permainan sebanyak 36 orang tenaga kerja perempuan.

Adapun kegiatan penyapuan terdiri dari penyapuan daun-daun kering yang rontok dan sampah hasil pengkasan rumput. Alat yang digunakan adalah sapu lidi, pengki, dan karung. Sampah hasil dari kegiatan penyapuan dimasukkan ke dalam karung dan dikumpulkan sampai diangkut oleh mobil sampah, dan membawanya ke bagian kompos untuk dijadikan sebagai sampah kompos. Kendala dalam melakukan kegiatan pembersihan yaitu antara jumlah pekerja dengan luasan tapak yang tidak sebanding sehingga pekerja tidak dapat menyelesaikan pekerjaannya dengan cepat.

Menurut Beard (1982), pemangkasan di area green, tee, fairway, dan rough berbeda-beda sesuai dengan fungsinya dalam permainan. Kegiatan pemangkasan pada Padang Golf Matoa Nasional meliputi pemangkasan rumput dan pemangkasan pohon. Kegiatan pemangkasan rumput pada area rough hanya dilakukan sekali dalam seminggu tanpa ada arah potongan. Ketinggian rumput yang dipertahankan 30-50 mm dan dilakukan dengan mesin Rough mower. Pemangkasan rumput pada area rough merupakan pemeliharaan pemangkasan yang ekstensif di antara pemeliharaan pemangkasan area permainan yang lain. Untuk pemangkasan di area rough operator mesin maupun mekanik harus bisa menyiapkan dan menjaga kondisi mesin dengan baik untuk digunakan dalam kegiatan pemangkasan. Pemangkasan pada pohon dilakukan per 6 bulan atau sesuai keluhan dari pemain. Pemangkasan pohon bertujuan agar pemain tidak terganggu dengan rantingranting yang menjuntai saat melakukan pukulan dan menghalangi jarak pandang. Pemangkasan pohon dilakukan 2-4 orang pekerja dengan menggunakan golok dan gergaji mesin (chainsaw).

Peralatan dan bahan yang dibutuhkan oleh tenaga kerja disimpan dalam gudang yang berada di maintenance lanskap. Gudang tersebut menjadi tempat penyimpanan peralatan dan bahan pemeliharaan, seperti berbagai mesin pemotong rumput, cangkul, pupuk, dan obat hama. Pemeliharaan peralatan seperti mesin pemotong rumput, cangkul, kape, dan golok, dipelihara oleh para tenaga kerja.

Tabel 1 menunjukkan bahwa masa efektif peralatan di Padang Golf Matoa Nasional melebihi masa efektif pembanding. Cangkul dan kape merupakan dua alat yang kondisinya tidak begitu baik sehingga mengganggu proses pemeliharaan. Sedangkan peralatan lainnya meskipun melebihi masa efektif pembanding, kondisinya masih baik dan tidak mengganggu proses pemeliharaan. Hal ini dipengaruhi oleh jumlah alat, intensitas penggunaan, dan pengetahuan pekerja. Pengetahuan ini terdiri atas jenis alat yang digunakan, fungsi dan cara kerja alat tersebut, penguasaan teknik pemeliharaan, serta penyimpanan alat setelah digunakan. 
Tabel 1. Perbandingan Masa Efektif Peralatan

\begin{tabular}{clcc}
\hline No. & Jenis Peralatan & $\begin{array}{c}\text { Masa Efektif Lapangan } \\
(\mathrm{a})\end{array}$ & $\begin{array}{c}\text { Masa Efektif Pembanding } \\
(\mathrm{b})\end{array}$ \\
\hline 1 & Mesin pemotong & 4 tahun & 3 tahun \\
& rumput & 1 tahun & 6 bulan \\
2 & Cangkul $\left(^{*}\right)$ & 1 tahun & 6 bulan \\
3 & Garpu tanah & 1 tahun & 6 bulan \\
4 & Sekop & 4 tahun & 2 tahun \\
5 & Kape $\left(^{*}\right)$ & 2 tahun & 6 bulan \\
6 & Gunting pangkas & 3 bulan & 1 bulan \\
7 & Sapu lidi & 1 tahun & 1 bulan \\
8 & Pengki & 1 tahun & 6 bulan \\
9 & Golok & 4 tahun & 3 tahun \\
10 & Mesin chainsaw & 1 tahun & 6 bulan \\
11 & Gergaji &
\end{tabular}

Keterangan: $\left({ }^{*}\right)$ peralatan yang kondisinya buruk sehingga mengganggu proses pengelolaan; (a) hasil pengamatan dan wawancara; dan (b) Arifin dan Arifin (2005)

Jangka efektifitas peralatan bisa dipakai lebih lama karena alat-alat yang telah selesai digunakan segera dibersihkan, dicuci, dan dikeringkan, kemudian disimpan dengan rapi dalam gudang peralatan. Dewi (2014) menyatakan bahwa pemahaman pekerja menjadi salah satu faktor penting dalam tercapainya tujuan pemeliharaan lapangan golf. Hal ini sejalan dengan hasil yang ditemui di lapang, yaitu dengan adanya pengetahuan pemeliharaan alat dapat memperpanjang usia penggunaan alat.

Menurut Arifin dan Arifin (2005), efektifitas kerja operator pemeliharaan taman sangat ditentukan oleh beberapa hal seperti motivasi kerja dan tingkat keterampilan yang dimiliki oleh para operator pemeliharaan taman, sistematika jadwal perencanaan pemeliharaan taman, dan ketersediaan alat serta bahan sesuai dengan kebutuhan. Selanjutnya efektivitas kerja operator taman juga ditentukan oleh tingkat pengawasan pekerja di lapangan serta kelancaran komunikasi antara pimpinan (manager) dengan para mandor dan antara mandor dengan operator pemeliharaan taman di lapangan.

Hal yang paling penting dalam kegiatan pemeliharaan adalah tenaga kerja. Pekerja yang terlatih dan berkualitas akan dapat menyelesaikan pekerjaan dengan baik. Untuk itu perlu diadakan pelatihan secara rutin mengenai teknik pemeliharaan yang baik. Tenaga kerja di Padang Golf Matoa Nasional berjumlah 46 orang. Para pekerja bekerja dimulai dari pukul 05.30-15.00 WIB. Sistem waktu kerja bagian lapangan menggunakan sistem shift. Kinerja para tenaga kerja dapat dihitung dengan kapasitas kerja melalui waktu kerja dalam menyelesaikan satu pekerjaan. Untuk tenaga kerja perempuan bagian pembersihan/penyapuan dimulai dari pukul 05.30-10.00 WIB dan pada hari libur bekerja sampai pukul 12.00 WIB.

Untuk mengetahui kapasitas kerja dapat dihitung rata-rata pelaksanaan per bulan dalam satuan jam, serta dapat mengetahui jumlah tenaga kerja yang diperlukan untuk luasan tertentu (Febriani, 1998). Luas area yang terpelihara saat ini kurang lebih mencapai 
38 ha. Jumlah tenaga kerja divisi Lanskap, divisi turfgrass dan ibu-ibu sebanyak 46 orang. Rasio tenaga kerja yang diterapkan adalah 1:0,8 yang artinya satu orang pekerja memiliki area yang harus dipelihara seluas 0,8 ha.

Perhitungan kapasitas kerja dilakukan pada pekerja pemeliharaan yang bekerja secara efektif. Hal ini dimaksudkan untuk melihat kecukupan jumlah tenaga kerja di Padang Golf Matoa Nasional. Dengan mengetahui kapasitas kerja maka dapat direncanakan jumlah kebutuhan tenaga kerja sesuai dengan luasan yang akan dipelihara. Perhitungan rata-rata waktu yang dibutuhkan dalam satu bulan per jam dapat dilihat pada Tabel 2.

Dari hasil perhitungan, setiap bulannya dibutuhkan 86,766 jam kerja. Setiap hari pekerja melakukan pekerjaanya selama 8 jam dan pada hari libur ditambah dengan 4 jam, maka dalam 1 bulannya satu orang pekerja akan melakukan pekerjaan selama 208 jam. Dengan diketahuinya jam kerja perorangan dan rata-rata jam kerja untuk semua pekerjaan dalam waktu satu bulan, maka pemeliharaan hazard di Padang Golf Matoa Nasional dibutuhkan sekitar 417 orang tenaga kerja. Rasio tenaga kerja menjadi 1:0,1 dengan arti untuk satu orang pekerja memliki area yang harus dipelihara seluas 0,1 ha. Dengan asumsi bahwa setiap pekerja dapat melakukan 2 sampai 3 jenis pekerjaan, maka kebutuhan jumlah tenaga kerja dari hasil perhitungan yaitu 417 dibagi dengan jenis pekerjaan yang dapat dilakukan oleh 1 orang pekerja yaitu 3 jenis pekerjaan. Dengan demikian, kebutuhan tenaga kerja menjadi 139 orang tenaga kerja.

Tabel 2. Kapasitas Kerja dan Kebutuhan Waktu Pengelolaan Taman

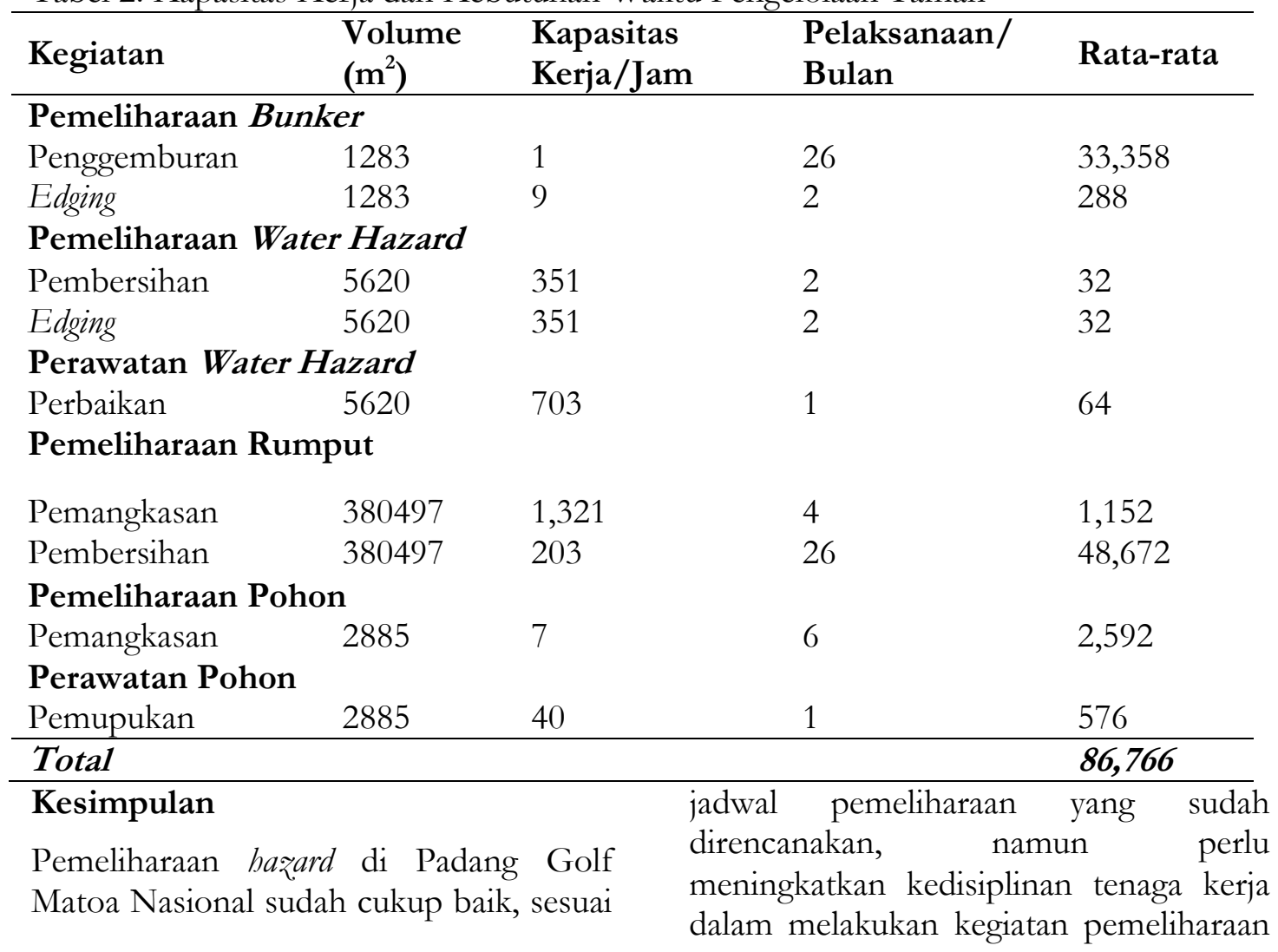


serta efektifitas waktu para pekerja. Pada umumnya kemampuan teknik tenaga kerja di Padang Golf Matoa Nasional sudah cukup baik dan terampil. Secara umum peralatan pengelolaan di Padang Golf Matoa Nasional melewati masa efektif penggunaan. Kondisi peralatan yang digunakan masih baik dan tidak mengganggu proses pemeliharaan meskipun melewati masa penggunaan terkecuali untuk kape dan cangkul. Permasalahan yang ada di Padang Golf Matoa Nasional yaitu rasio tenaga kerja dalam kegiatan pemeliharaan hazard masih kurang.

\section{Daftar Pustaka}

Arifin, H.S. dan Arifin N.H.S. 2005. Pemeliharaan Taman Edisi Revisi. Jakarta: Penebar Swadaya. 171 p.

Beard, J.B. 1982. Turf Management for Golf Course. San Fransisco: Burgess Publishing Company. 642 p.

Emmons, R. 2000. Turfgrass Science and Management, 3rd edition. New York: Thompson Learning Inc. 528 p.

Febriani, Y. 1998. Pemeliharaan Lanskap Common Area di Kawasan Wisata Nusa Dua, Bali. Laporan Ketrampilan Profesi, IPB.
Lily, S. 1999. Golf Course Tree Management. Michigan: Ann Arbor Press Inc. $217 \mathrm{p}$.

Merinda, H. 2002. Pengelolaan Lanskap Kawasan Permukiman Golf Estate Bogor Raya dan Lapangan Golf Klub Golf Bogor Raya, Bogor. Skripsi, IPB, ID, 131 p.

Petrick, J. F., Backman, S. J., dan Bixler, R.D. (1999). An investigation of selected factors' impact on golfer satisfaction and perceived value. Journal of Park and Recreation Administration. 17 (1):40-59.

Setyaningsih, T. 1999. Pemeliharaan Lapangan Golf serta Pengamatan Hama dan Penyakit Penting pada Rumput Golf di Damai Indah Golf \& Country Club, Tangerang, Skripsi, IPB, ID, 52 p.

Shmanske, S. 1999. The economics of golf course condition and beauty. Atlantic Economic Journal. 27(3):301313.

Sternloff, R.E. dan Warren, R. 1984. Park and Recreation Maintenance Management (Second Edition). New York: John Wiley and Sons Inc. $326 \mathrm{p}$. 